\title{
Article
}

\section{Forensic procedures for facial-composite construction}

Fodarella, Cristina, Kuivaniemi-Smith, Heidi, Gawrylowicz, Julie and Frowd, Charlie

Available at http://clok.uclan.ac.uk/18189/

Fodarella, Cristina ORCID: 0000-0001-5551-3450, Kuivaniemi-Smith, Heidi, Gawrylowicz, Julie and Frowd, Charlie ORCID: 0000-0002-5082-1259 (2015) Forensic procedures for facial-composite construction. Journal of Forensic Practice, 17 (4). 259 -270. ISSN 2050-8794

It is advisable to refer to the publisher's version if you intend to cite from the work. http://dx.doi.org/10.1108/JFP-10-2014-0033

For more information about UCLan's research in this area go to http://www.uclan.ac.uk/researchgroups/ and search for <name of research Group>.

For information about Research generally at UCLan please go to http://www.uclan.ac.uk/research/

All outputs in CLoK are protected by Intellectual Property Rights law, including Copyright law. Copyright, IPR and Moral Rights for the works on this site are retained by the individual authors and/or other copyright owners. Terms and conditions for use of this material are defined in the policies page.

\section{CLoK}

Central Lancashire online Knowledge www.clok.uclan.ac.uk

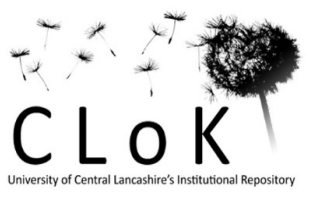


Fodarella $^{1}$, C., Kuivaniemi-Smith ${ }^{1}$, H., Gawrylowicz ${ }^{2}$, J., \& Frowd ${ }^{1}$, C.D. (in press). Forensic procedures for facial-composite construction. Journal of Forensic Practice.

${ }^{1}$ University of Winchester, UK.

${ }^{2}$ Royal Holloway, University of London. UK

\begin{abstract}
Purpose - The paper provides a detailed description of standard procedures for constructing facial composites. These procedures are relevant to forensic practice and are contained in the technical papers of this special issue; our aim is also to provide an expanding reference of procedures for future research on facial composites and facial-composite systems.
\end{abstract}

Design/methodology/approach - A detailed account is given of the interaction between practitioner and witness for producing a facial composite. This account involves an overview of the Cognitive Interview (CI) and the Holistic CI (H-CI) techniques used to obtain a description of the face of an offender (target); we then describe how this information is used to produce a composite from five popular face-production systems: Sketch, PRO-fit, E-FIT, EvoFIT and EFIT-V. An online annex is also made available to provide procedural information for additional composite systems.

Practical implications - The work is valuable to forensic practitioners and researchers as a reference for interviewing techniques (involving a CI or an $\mathrm{H}$-CI) and using facial-composite systems.

Originality/value - We provide an accessible, current guide for how to administer interviewing techniques and how to construct composites from a range of face-production systems.

Keywords Facial composite, Sketch, PRO-fit, E-FIT, EvoFIT, EFIT-V, Cognitive Interview (CI), Holistic CI (H-CI)

Paper type Procedural

Acknowledgements The authors would like to thank Claire Ford, Emily Graham and Claire Madin, all from the Psychology Department at the University of Winchester, along with two anonymous reviewers, for their insightful comments on this paper. 
In a police investigation, it is usual for forensic practitioners to interview witnesses and victims of crime to construct a facial composite of an offender as soon as is practical to do so. The normal delay (retention interval) to interview is upwards of one or two days following a crime (e.g., Frowd et al., 2012a), and the face can be created using a number of different techniques or systems. Research projects can follow this process in the laboratory (e.g., Frowd et al., 2005) using a similar retention interval and with researchers experienced in the relevant system.

Sketch and 'mechanical' systems were the first techniques employed to construct composites with witnesses and victims (e.g., Davies, 1983). Sketch refers to forensic artists drawing a face by hand. Mechanical systems such as Photofit and Identi-Kit were then introduced, enabling less-artistically skilled practitioners to be able to create composites suitable for use in a police investigation. With these types, witnesses could build a face by selecting facial features (eyes, nose, mouth, hair, etc.) that are printed on transparencies or jigsaw-like pieces. For practical and functional reasons, computer-driven systems have largely replaced the mechanical techniques: software systems were designed with a large range of facial features, and these features could be more-accurately sized and positioned on the face (Frowd, 2012).

There are two main types of software system, feature and holistic. With feature systems such as PRO-fit, E-FIT, FACES and Identikit 2000, witnesses recall the appearance of a target face and are shown facial features to match; they are then asked to select the best example of each feature. For the EvoFIT and EFIT-V holistic systems, the approach aims to match how the brain perceives and recognises faces: as a whole face, or 'holistically’ (e.g., Valentine, 1991). These recent incarnations operate by witnesses repeatedly selecting from arrays of whole faces (or whole-face regions), with characteristics of selected items being 'bred together', to essentially 'evolve' a face. As such, holistic systems were originally designed for witnesses to use face recognition to a greater extent than face recall, since face recognition is easier and less demanding than face recall (Davis, Sutherland and Judd, 1961). Also, as faces are difficult to describe accurately (Shepherd, Davies and Ellis, 1978), and facial information is rapidly forgotten (Ellis, Shepherd and Davies, 1980), one benefit of holistic over feature systems is that composite construction does not depend upon the ability of a witness to produce a verbal description of the face. In fact, it is often the case that witnesses cannot provide a detailed description (Frowd, 2012) and, consequently, UK police guidelines advise against construction using feature systems ( $\mathrm{ACPO}(\mathrm{S}), 2009)$. In addition, holistic systems have the potential to help witnesses and victims with communication difficulties, such as people with intellectual disabilities (Gawrylowicz et al., 2012).

In the UK, Europe and elsewhere (e.g., US), specific systems for constructing composites are Sketch, PRO-fit, E-FIT, EvoFIT and EFIT-V. These systems are used by forensic practitioners 
(sometimes called facial-imaging specialists), or forensic researchers in a laboratory setting; for computerised systems, practitioners are sometimes referred to as composite 'operators'. The current paper focuses on five of these systems, those that are relevant to research papers involved in the special issue of this journal.

First, we outline the Cognitive Interview (CI) used by practitioners prior to composite construction, followed by procedures to construct artists' sketches, PRO-fit, E-FIT, EvoFIT and EFIT-V. Throughout, we have referred to people who construct a face as 'witnesses', but acknowledge that these individuals may be victims of crime, or participants who construct a composite in a laboratory setting (also known as 'participant' witnesses). In each case, witnesses are interviewed individually by a forensic practitioner in a quiet location, both to recall the appearance of the offender's (target) face (using a CI or an $\mathrm{H}-\mathrm{CI}$ ) and to construct a single composite of this face using one of the aforementioned systems. In a police investigation, other procedures are put in place to accommodate the needs of witnesses and victims, as well as to handle evidence (e.g., ACPO(S), 2009).

\section{Cognitive Interview (for obtaining a description of the target's / offender's face)}

The CI is a set of techniques (mnemonics) developed by Geiselman et al. (1985), with subsequent revisions (e.g., Wells, Memon and Penrod, 2007). The approach is theory-driven and aims to facilitate memory retrieval (recall of information), communication and social dynamics (for an accessible recent review, see Fisher, Milne and Bull, 2011). For face construction, a CI is used at the start of a session with the aim of improving the effectiveness of a composite (for an in-depth review of the CI for this application, see Frowd, 2011).

At the start of a composite session, informal rapport is built, with the aim of putting a witness at ease (a technique which should facilitate recall). Next, a brief overview of the procedure is given: witnesses are told that the session is in two parts: first to obtain a description of the face using cognitive-interviewing (CI) techniques, and then to build a picture of this face using the relevant system. Witnesses are encouraged to ask questions throughout. Following this, they are invited to visualise - that is, to create a picture in their mind of the face-and to freely recall as many details about him or her as possible, without guessing. The practitioner makes written notes of information recalled in the witnesses' own words; this is usually recorded on a verbal-description sheet (see Frowd, 2011) which contains labels for overall observations, hair, eyes, nose, etc. Witnesses should not be interrupted during face recall, although they can be asked to speak more slowly to allow a practitioner to take notes. 
There are some variations of mnemonics of the CI for face construction. For example, witnesses may be invited to recall the face again, to give a second "cycle" of free recall, or attempt additional recall of each feature, prompted by the practitioner reading back a witness' initial recall for each feature. For this latter cued-recall mnemonic, for example, witnesses may be told "You remembered the eyes were oval and light in colour. Can you recall anything further about them?” This technique is often used for the production of sketches (see relevant section below).

Research indicates that a 'holistic' CI is a more-effective interviewing technique (cf. CI) for composite construction (e.g., Frowd et al., 2008). This enhanced interview comprises two additional (whole-face) mnemonics to the CI, with the overall aim to improve witnesses' face-recognition ability: after describing the face using a CI (as detailed above), they are asked to reflect silently (i.e., to themselves) on the personality of the (target) face for 60 seconds (holistic free-recall mnemonic), and then to make seven global judgments about it on a three-point Likert scale for low, medium and high (holistic cued-recall mnemonic). Judgements are usually requested in the following order: intelligence, friendliness, kindness, selfishness, arrogance, distinctiveness and aggressiveness—although other prompts can be used (e.g., masculinity, honesty and extroversion) depending on the situation and crime (see Frowd et al., 2012b). The H-CI promotes a more-identifiable composite from feature (Frowd et al., 2008), holistic (Frowd et al., 2012b) and [most recently] sketch (Kuivaniemi-Smith et al., unpublished) systems. A fact sheet is available on the H-CI at http://tiny.cc/holistic-ci. Readers may also be interested to learn that the H-CI is very effective in conjunction with techniques that facilitate recognition of a finished composite (e.g., Frowd et al., 2013a; http://tiny.cc/pbi-composite).

We now describe standard forensic procedures for using facial-composite systems. Information about changes to these procedures (as new techniques are developed in the future) as well as information on procedures for further systems may be found at http://tiny.cc/comp-procedural-annex.

\section{Artist's Sketch}

There are different approaches for creating sketched composites with witnesses, and it is up to the artist which method and media are chosen. Sketches that are circulated in the public domain appear to be most-commonly created by pencils or charcoal, but some artists prefer to use colour. There are also an increasing number of artists who use digital sketching, and this involves use of Adobe Photoshop or other paint packages. Such a procedure allows quicker amendments to be carried out on the sketch than the traditional paper-based method; it also results in a good-quality drawing that 
is in digital form ready for distribution. The potential benefit of computerised technology for sketch production is being explored by the second author.

Following a CI to obtain a verbal description from the witness, the artist creates an initial faintlydrawn sketch. The artist repeats the witness' description, usually proceeding from the top of the head and face downwards, drawing the individual features simultaneously. This often elicits more information about features. Usually, more probing of detail is also required, as part of cued recall, especially concerning distances between features. For example, the artist can ask about the spacing between the eyes, to gain an impression as to whether they are 'close together', 'wide apart', or a 'normal width' - in this case, 'normal' corresponds to the width of about one eyeball between the eyes. Once all features have been lightly drawn, the sketch is shown to the witness. The idea of not seeing the drawing before this stage is to promote holistic recognition of the face, after the person has focused on individual features in the recall process.

If witnesses have been able to provide a detailed description, the initial sketch may already be close to their memory of the target. It is then a case of allowing witnesses to guide the artist to alter the sketch until it reaches the best likeness that can be achieved. Leading, suggestive and closed questions should be avoided. For example, it is preferable to ask witnesses to give an indication of the width of the face (an open question) rather than to ask whether the person had a wide face (a closed question). In general, it is usual practice for witnesses to lead the sketching process by specifying the order on which features should be worked. The artist generally keeps the sketchpad away from witness' sight while drawing unless it is for a very minor alteration. Witnesses review the sketch frequently with the aim of improving the likeness feature-by-feature.

It is often the case that an initial sketch needs considerable work to be carried out. If the witness struggles with describing either the face as a whole or a specific feature, reference materials can be shown, with the aim of triggering recognition. For example, Samantha Steinberg's facial catalogue (2012) can be used after the initial sketch has been established (e.g., Kuivaniemi-Smith et al., 2014). This catalogue contains pictures of facial features collected from police mug shots that are presented in whole faces, but with the intended feature circled (e.g., noses), to conceal other features. Of course, care should be taken to avoid fatigue (from witnesses seeing too many features). The authors' note that a feature-based composite system can itself be used to present reference materials, an approach we have successfully trialled recently (Kuivaniemi-Smith et al., unpublished).

In general, the artist makes alterations to the sketch as necessary, in an iterative manner, in a session which takes as long as required. The interview is usually terminated when witnesses report that the best likeness has been achieved. 
PRO-fit

PRO-fit is a computer program considered to be a 'feature' system due to emphasis on individual features. Composites are produced in greyscale, as colour does not seem to promote more identifiable composites overall (e.g., Frowd et al., 2006).

After the initial interview to recover a free description of the face using CI or H-CI, as detailed above, a practitioner begins by providing an overview of the process used to build the face with this system: witnesses will be shown features that match their given description, to select, size and position on the face. The practitioner selects an appropriate database for ethnicity, gender and age. For each facial feature (i.e., hair, eyes, nose, etc.), the program has access to around 150 - 500 examples. In order to limit this to a manageable number-around 20-the practitioner uses the given description to select appropriate characteristics from the program (e.g., nose: 'short', 'medium' or 'long'). If information is not provided for a specific feature, witnesses can be asked for clarification. However, if no further details are provided, operators can set the descriptors for such a feature at their most typical classification (i.e., 'medium' or 'average') or simply leave them unset (to reveal all exemplars). Note that, in a forensic setting, it is permissible under police guidelines (ACPO(S), 2009) to attempt construction of a feature composite (incl. Sketch) even if a witness cannot describe one facial feature (e.g., a nose). The idea here is that construction of the face as a whole is likely to trigger recall of a previously-undescribed feature.

Once the description has been entered, and practitioners have located around 20 examples per feature, witnesses are informed that the first face seen will be an 'initial' composite, a face with features to match their description, as illustrated in Figure 1. Using this face, the practitioner demonstrates how features can be selected, sized, positioned and reflected horizontally, and the brightness and contrast adjusted; s/he also mentions that an artwork package is available towards the end of the session to improve the likeness, if necessary, by adding shading, wrinkles, etc.

Figure 1

Witnesses are asked to indicate which facial feature they would like to concentrate on first (which usually turns out to be hair, then face shape). For a given feature, it is normal for witnesses to be shown all of the available examples (about 20), and to 'tag' items which are potential matches; after all examples have been presented, tagged features are given further consideration, or the description is updated to allow alternative choices to be seen. As mentioned above, facial features are shown in the context of a complete face, a procedure which is known to facilitate identification (e.g., Davies 
and Christie, 1982; Skelton, Frowd and Speers, 2016). Once selected, witnesses adjust a feature’s size, position, brightness, etc. This procedure is repeated (under the direction of the witness) to identify other features of the face. It is also iterative, by allowing adjustments even for a feature that has been previously selected; practitioners encourage witnesses to create the best likeness possible. If necessary, practitioners make use of the artwork package, whereby the complete face or an individual feature can be altered on demand; this function is particularly useful for removing or adding hair and for reshaping eyebrows. They may also use the Warp Tool to make additional changes to the composite such as to lower the hairline or reshape a facial feature.

As mentioned above, composites are created more effectively with PRO-fit using the H-CI (cf. CI; Frowd et al., 2008). More-recent research (to be published) reveals that composites with evenhigher identification rates are now possible when an $\mathrm{H}-\mathrm{CI}$ is administered in combination with an improved construction procedure. Under this improved procedure, a composite is constructed first by presenting and selecting internal features (face shape, eyes, brows, nose and mouth) with external features masked, followed by presenting and selecting external features (hair and ears) with internal features concealed. Afterwards, the complete face is revealed and witnesses continue to work on the likeness. This internal-external construction procedurei reflects the general approach followed when composites are created with EvoFIT.

\section{E-FIT}

A second computer-based composite system used by British and European law enforcement agencies is E-FIT (Electronic Facial Identification Technique). It was originally developed by the Home Office and researchers from the Psychology Department at Aberdeen University. As with other computer-based systems such as PRO-fit, E-FIT is considered a featural type due to emphasis on individual features. As with PRO-fit, witnesses describe the face (via CI or $\mathrm{H}-\mathrm{CI}$ ) to a practitioner; the practitioner or operator then uses E-FIT to present individual facial features (to match the description) for witnesses to choose. E-FIT can be considered to be somewhat holistic in nature, the same as for PRO-fit, as witnesses work within the context of the whole face rather than selecting and altering isolated facial features.

In general, the following method is recommended when creating a composite with E-FIT. To start, the practitioner explains the purpose of the session and the witness is familiarised with the E-FIT system. Thereafter, practitioners use the CI or the H-CI to elicit a detailed facial description. The facial descriptions provided during the interview are then translated into the Aberdeen Index and entered into facial description boxes. The entered information drives an algorithm based on fuzzy 
logic that selects the best fitting features from the database. The resultant E-FIT (an initial composite) is then presented to the witness who is allowed to make changes to features by changing their size or position or by scrolling through alternative features within the context of the whole face. Next, fine-grained changes can be made using standard drawing packages, such as PaintShop Pro or Photoshop. The E-FIT construction process is completed when the witness expresses that s/he is satisfied that the best likeness has been achieved. The system has been shown to be compatible with interviewing a range of constructors including those with mild intellectual difficulties (Gawrylowicz, 2010; Gawrylowicz et al., 2012). As with PRO-fit, the procedure for creating an EFIT follows recommendations of the $\mathrm{ACPO}(\mathrm{S})$ Working Group for Facial Identification (2009).

\section{EvoFIT}

EvoFIT is a holistic software program: witnesses construct a face by repeatedly selecting from whole-face regions from arrays (of 18 faces) rather than by selecting individual facial features. A detailed description of the underlying technology may be found in Frowd (in press). For the same reason as mentioned above for PRO-fit, composites are created in greyscale.

After administering a CI or an H-CI, practitioners provide a straightforward summary of the procedure used to construct a face: witnesses will select from screens of faces, with selected items being combined, to evolve a composite over a number of generations (complete cycles through the system); tools are then available to improve the overall likeness and, towards the end of the process, to manipulate the shape and position of facial features. Practitioners inform witnesses that the central (internal features) region (incl. eyes, brows, nose mouth) will be constructed first, as this helps to avoid distraction from the external part (hair, ears and neck) and to produce an identifiable composite. Note that earlier (less-effective) versions of EvoFIT presented external features that were blurred in these arrays (Frowd et al., 2010; 2012c). To further promote an identifiable face, witnesses are requested to make selections on the face as a whole [rather than on any individual feature] (but recent [currently unpublished] research by the first author suggests that selecting for the upper facial half is more effective); they are requested, though, not to base selections on face width since this aspect—along with other overall properties such as age, weight and pleasantness — can be modified [with holistic tools] once the face has been evolved.

There are currently 60 individual databases to cater for differences in a target's ethnicity, age and gender. At this stage, prominent facial hair (e.g., beard or moustache), jewellery (e.g., brow ring) or glasses can be added, so that faces are presented accordingly; hats and other accessories (relevant to external features) can be added once internal features have been created. The practitioner selects 
the most appropriate database (based on the witness's recall) and confirms this choice with the witness-by presenting a screen of randomly-generated faces (see Figure 2). Next, the first screen of 18 facial shapes are shown, faces showing the internal-features region with a smooth texture that differ by (i) the shape of facial features, (ii) the outline of the face and (iii) the position of the features on the face; witnesses are told that faces can be selected for facial texture (i.e., greyscale colour, shading) in due course.

\section{Figure 2}

The following procedure is common for face selection in the first generation where faces contain random characteristics. Witnesses are told that three screens of facial shapes will be presented, and for each screen they are required to select the two faces that are most similar to the target. Practitioners emphasise that faces should be selected based on the overall likeness to the target rather than for any facial feature, as this overall-selection method should produce the best results. Witnesses accordingly select two items. As was carried out in the CI, they are requested to visualise the target face again when prompted to do so by the computer (which occurs each time a screen of faces is generated). A new set of facial shapes is generated in the array (leaving the original two selections intact) and witnesses select a further two items (that are perceived to be the best match to the target). A third screen of shapes is created (leaving four selections intact) and a further two items are selected. A fourth screen of shapes is created (leaving six selections intact), and witnesses are given the opportunity to make alternative selections (while ultimately maintaining six faces selected).

Unselected items are now removed from view and witnesses are asked to select one item that represents the best overall match, a shape that will be used to present facial textures. Once selected, the first screen of textures is generated with this chosen shape. Witnesses are informed that faces now differ by facial texture; they vary by shading for individual features (eyes, brows, mouth, etc.) and for overall skin tone. The procedure described in the previous paragraph is used to select six textures over four screens. Next, witnesses are informed that two screens will be shown containing combinations of their selected six shapes and six textures, to identify a preferable likeness so far. For each combination screen (an array of 18 faces), witnesses select the best item and the practitioner switches between screens to allow the witness to indicate the overall preferable face.

The software now displays a 'summary' screen. A distinction is made between faces selected for facial shape (item highlighted with a blue border), facial texture (green border), both shape and texture (red border), and combination (pink border). Witnesses are asked to make a further choice for optimal likeness (and normally pick their choice from the combination screen): this face is highlighted as the 'best' face for the generation. 
The practitioner mentions that characteristics of selected faces will now be combined ['bred' together] and the process repeated. At this stage, the best face is presented for witnesses to rate on a 10point Likert scale $(1$ = very-poor likeness ... 10 = faces are identical). (This rating is intended to allow witnesses to reflect upon the likeness produced thus far and does not influence generation of faces.) After rating, the practitioner mentions that faces will be presented as before; the exception is that shapes now have the texture of the best face to help selection, rather than being smooth (as was the case in the previous generation for selection of shapes). Witnesses again select from shape, texture, combinations and summary screens; once again, it is emphasised that choices should be based on the overall appearance of the face. At the end of this second generation, they are given the option of either evolving again, or reworking their chosen best face to improve the overall likeness using holistic tools. If the decision is to evolve for another generation (which occurs infrequently), witnesses are asked this question again on the subsequent summary screen; if not, the practitioner exits the program from the evolving stage and the best face is loaded into holistic tools.

Witnesses are now instructed that their best face can be adjusted using software tools which change the overall likeness, starting with face width. The practitioner moves the presented scale (slider) and witnesses indicate the position of best likeness for face width (or returns the slider to the centre position, to leave the face unaltered). The resulting image is transferred to the next scale, for age. Witnesses adjust this dimension and then others (in the following order) for facial weight, attractiveness, extraversion, health, honesty, masculinity, threatening and vertical position of the internal features; further scales are offered to adjust for trustworthiness, hardness, dominance and suntan, as well as facial texture (greyscale level) for eyes, eyebrows, mouth, stubble, moustache, beard, eye bags, laughter lines and deep-set eyes. If necessary, scales can be re-applied, to increase their effect. Finally, witnesses are presented with both the original and altered face, and indicate whether the likeness has improved (practitioners can restore the original face and offer use of holistic tools again if nec.).

The system moves to the 'final options' dialog. The current face is shown and witnesses are asked to describe changes to improve the likeness. To achieve these requests, holistic tools can be used again, or the shape tool, to manipulate shape and placement of facial features. Once witnesses report that internal features have been constructed as best as possible, external features (hair, forehead, ears and neck) are selected. The practitioner enters characteristics of hair from the witness' verbal description, the same as for PRO-fit and E-FIT. An array of hair and other external features are presented showing the closest matches, with less-accurate hair shown on subsequent screens. Witnesses indicate the best-matching item and adjust the greyscale colour of the hair, or reflect it 
horizontally, as necessary; at this stage, the skin tone (brightness) can be also adjusted for forehead, ears and neck.

The likeness can be further improved using the previous holistic and shape tools, making use of Adobe Photoshop (to add marks, shading, etc.), or by using the warp tool to make alterations to the hair, the same as for PRO-fit (e.g., to lower the hairline). Hoods, hats and other accessories can be added (or previously-selected items changed). The practitioner works with the witness and the available tools to achieve the best likeness possible, upon which the face is saved to disk.

\section{EFIT-V}

EFIT-V is holistic software program: witnesses construct a face by repeatedly selecting whole faces from arrays - in this case arrays of nine whole faces (cf. arrays of 18 internal-features faces for EvoFIT). Composites are created in colour or greyscale.

As with previous techniques, after the initial interview, the practitioner provides a summary of the procedure: witnesses first choose an appropriate hairstyle and then select from screens of faces; tools are available to alter facial features and to improve the overall likeness. The practitioner chooses the correct face database for ethnicity, gender and age range.

The practitioner then has two different choices on how to progress, that is, either via 'Guidance' or 'Proceed'. This choice will be based on witness' facial memory as indicated by the amount of detail provided during the CI. If memory is strong, 'Guidance' can be chosen. From arrays of nine faces over several screens, witnesses are asked to select the best item for each facial feature (i.e., face shape, nose, mouth, etc.). Any close matches can be 'tagged', and once every example has been seen, tagged features are presented again for further consideration. Whilst one item is being chosen, other features are blurred to avoid distraction. The practitioner demonstrates how features can be sized and positioned, and alterations made to a feature's brightness, contrast and colour. Finally, external features are added: the practitioner enters characteristics of hair, as with PRO-fit and EvoFIT, such as for colour, style and length. An array of hair is presented, and witnesses select the best match. Following this, witnesses are informed that the software will present arrays of faces, each with the same chosen hair, but with varying facial features, as illustrated in Figure 3. These features have been bred based on features initially picked.

\section{Figure 3}


In contrast, the operator can choose 'Proceed' if witness' memory is weak. With this option, steps of choosing individual facial features are skipped. Witnesses are first asked to select the best hairstyle, so that arrays of faces can be produced with the same hairstyle but with varying features (Figure 3). These features are extracted from a wider database as no initial features were selected.

From these arrays of faces, following the option 'Proceed' or 'Guidance', witnesses are instructed to select any face of good likeness, which will generate further faces. Throughout the process, the practitioner reminds the witness that two or more faces can be merged together to improve the likeness further. Also, features can be 'frozen' if required, preventing these from changing on subsequent screens. In addition, the system allows a composite to be aged by a slider control.

Once the witness chooses one overall best face, ears, shoulders and clothes can be added. The operator demonstrates how these can be altered with regard to colouring, sizing, positioning, contrast, brightness and through insertion of specific logos (e.g., football logos) if necessary. Appropriate jewellery, glasses, hats and beards can also be added. The face can be altered further by changing size, position, contrast, brightness and colour of individual features.

Once the witness is satisfied with the likeness, the practitioner explains that an 'Advanced Tool' can now be used to change overall characteristics of the face by scale, similar to the holistic tools in EvoFIT. These characteristics are hostility, health, angular, hardness, happiness, kindness, weight and friendliness. Whilst changing these properties, both the original and altered face are visible so that witnesses can indicate at any time whether the likeness is improving, or whether changes need to be undone. Finally, as with previous systems, the practitioner can use additional art packages to make further changes (e.g., adding moles and wrinkles).

\section{Discussion}

The purpose of this paper is to provide in-depth procedures for professionals to administer interviewing techniques and construct facial composites using five contemporary systems. This reference is intended for forensic practitioners as well as for researchers when carrying out composite research, in particular for those systems covered in this journal's special issue. An update of procedures for these systems and procedures for further systems are available online (http://tiny.cc/compprocedural-annex); we welcome contributions to this expanding document.

Procedures have been provided for administering CI and H-CI techniques as well as for using Sketch, PRO-fit, E-FIT, EvoFIT and EFIT-V systems. Artists' sketches are mostly drawn by hand (using pencils / charcoal; in black or in colour), but there is an increasing trend for use of digital- 
sketching techniques. PRO-fit and E-FIT are computer-driven feature systems for witnesses to select individual features within a whole-face context to create composites in greyscale. EvoFIT and EFIT-V are computer-driven holistic systems with which witnesses create a face by repeatedly selecting from face arrays. EvoFIT creates greyscale images of the internal-features region first, and then external features are added; EFIT-V creates whole-face composites in either greyscale or colour after an initial focus on individual facial features for one of its modes of operation.

With regard to effectiveness, recent regression- and meta-analyses indicate that EvoFIT is over four times more effective (by correct naming of composites) than other systems, and that sketch is somewhat more effective than feature systems (Frowd et al., 2016). These analyses also indicate the importance of the H-CI (cf. CI), with witnesses focusing on personality judgments of the target face, for improving composite naming (Frowd et al., 2008; 2012b; 2013a; Kuivaniemi-Smith et al., unpublished). This work also underscores the [negative] impact of a long retention interval and the necessity of such a delay for composite research. There is one published paper (Valentine et al., 2010) which formally assesses the effectiveness of EFIT-V; the result is that naming of its composites when tested using a very-short retention interval (around a few minutes) is broadly similar to that of feature systems (Frowd et al., 2016). More generally, work (Frowd et al., 2013a; 2013b) is revealing that the effectiveness of composites can be enhanced by combining holistic-type techniques at each stage in the process of face construction (interview and system) and naming (caricature, stretch).

\section{References}

ACPO(S) [Association of Chief Police Officers (Scotland)] (2009), “Facial Identification Guidance”, Produced by the National Policing Improvement Agency. Available to download at www.acpo.police.uk/documents/crime/2009/200911CRIFIG01.pdf

Davies, G.M. (1983), "Forensic face recall: the role of visual and verbal information", in S.M.A. Lloyd-Bostock and B.R. Clifford (Eds.). Evaluating witness evidence (pp. 103-123). Chichester: Wiley.

Davies, G.M. and Christie, D.F.M. (1982), “An examination of some factors limiting composite production accuracy”, Journal of Applied Psychology, Vol. 67, pp. 103-109.

Davies, G.M., Shepherd, J.W. and Ellis, H.D. (1978), “Remembering faces: acknowledging our limitations”, Journal of the Forensic Science Society, Vol. 18, pp. 19-24. 
Davis, R., Sutherland, N.S. and Judd, B.R. (1961), “Information content in recognition and recall”, Journal of Experimental Psychology, Vol. 61, pp. 422-429.

Dando, C.J., Wilcock, R. and Milne, R. (2009), “The Cognitive Interview: The efficacy of a modified mental reinstatement of context procedure for frontline police investigators”, Applied Cognitive Psychology, Vol. 15, pp. 679-696.

Ellis, H.D., Shepherd, J.W. and Davies, G.M. (1980), "The Deterioration of Verbal Descriptions of Faces Over Different Delay Intervals”, Journal of Police Science and Administration, Vol. 8, pp. 101-106.

Fisher, R., Milne, R. and Bull, R. (2011), “Interviewing cooperative witnesses”, Current Directions in Psychological Science, Vol. 20, pp. 16-19.

Frowd, C.D. (2011), “Eyewitnesses and the use and application of cognitive theory”, In G. Davey (Ed.) Introduction to Applied Psychology (pp. 267-289), BPS Wiley-Blackwell.

Frowd, C.D. (2012), “Facial Recall and Computer Composites”, in C. Wilkinson and C. Rynn (Eds). Facial Identification (pp. 42-56). Cambridge University Press: New York.

Frowd, C.D. (in press), “Facial composites and techniques to improve image recognisability”, in T. Valentine and J. Davis (Eds.) Forensic facial identification: theory and practice of identification from eyewitnesses, composites and cctv, Wiley-Blackwell.

Frowd, C.D., Bruce, V., Plenderleith, Y. and Hancock, P.J.B. (2006), “Improving target identification using pairs of composite faces constructed by the same person”, IEE Conference on Crime and Security (pp. 386-395), London: IET.

Frowd, C.D., Bruce, V., Smith, A. and Hancock, P.J.B. (2008), “Improving the quality of facial composites using a holistic cognitive interview”, Journal of Experimental Psychology: Applied, Vol. 14, pp. 276-287.

Frowd, C.D., Carson, D., Ness, H., McQuiston, D., Richardson, J., Baldwin, H. and Hancock, P.J.B. (2005), "Contemporary Composite Techniques: the impact of a forensically-relevant target delay", Legal and Criminological Psychology, Vol. 10, pp. 63-81.

Frowd, C.D., Erickson, W.B., Lampinen, J.M., Skelton, F.C., McIntyre, A.H. and Hancock, P.J.B. (2016), "A Decade of Evolving Composite Techniques: Regression- and Meta-Analysis”, Journal of Forensic Practice. 
Frowd, C.D., Jones, S., Fodarella, C., Skelton, F.C., Fields, S., Williams, A., Marsh, J., Thorley, R., Nelson, L., Greenwood, L., Date, L., Kearley, K., McIntyre, A. and Hancock, P.J.B. (2013b), “Configural and featural information in facial-composite images”, Science and Justice, DOI:

10.1016/j.scijus.2013.11.001.

Frowd, C.D., Nelson, L., Skelton F.C., Noyce, R., Atkins, R., Heard, P., Morgan, D., Fields, S., Henry, J., McIntyre, A. and Hancock, P.J.B. (2012b), “Interviewing techniques for Darwinian facial composite systems”, Applied Cognitive Psychology, Vol. 26, pp. 576-584.

Frowd, C.D., Pitchford, M., Bruce, V., Jackson, S., Hepton, G., Greenall, M., McIntyre, A. and Hancock, P.J.B. (2010), “The psychology of face construction: giving evolution a helping hand”, Applied Cognitive Psychology, Vol. 25, pp. 195-203.

Frowd, C.D., Pitchford, M., Skelton, F.C., Petkovic, A., Prosser, C. and Coates, B. (2012a), "Catching Even More Offenders with EvoFIT Facial Composites", In A. Stoica, D. Zarzhitsky, G. Howells, C. Frowd, K. McDonald-Maier, A. Erdogan and T. Arslan (Eds.) IEEE Proceedings of 2012 Third International Conference on Emerging Security Technologies (pp. 20-26), DOI 10.1109/EST.2012.26.

Frowd, C.D., Skelton F.C., Atherton, C., Pitchford, M., Hepton, G., Holden, L., McIntyre, A. and Hancock, P.J.B. (2012c), "Recovering faces from memory: the distracting influence of external facial features”, Journal of Experimental Psychology: Applied, Vol. 18, pp. 224-238.

Frowd, C.D., Skelton F.C., Hepton, G., Holden, L., Minahil, S., Pitchford, M., McIntyre, A., Brown, C. and Hancock, P.J.B. (2013a), "Whole-face procedures for recovering facial images from memory”, Science and Justice, Vol. 53, pp. 89-97.

Gawrylowicz, J. (2010), “The construction of facial composites by witnesses with mild learning disabilities”, PhD thesis, Abertay University, Dundee, Scotland.

Gawrylowicz, J., Gabbert, F., Carson, D., Lindsay, W. R. and Hancock, P. J. (2012), “Holistic versus featural facial composite systems for people with mild intellectual disabilities”, Applied Cognitive Psychology, Vol. 26, pp. 716-720.

Geiselman, R.E., Fisher, R.P., MacKinnon, D.P. and Holland, H.L. (1985), “Eyewitness memory enhancement in the police interview: Cognitive retrieval mnemonics versus hypnosis”, Journal of Applied Psychology, Vol. 70, pp. 401-412.

Kuivaniemi-Smith, H., Frowd, C.D., Hepton, G. and Ford, C., "Improving the effectiveness of sketch-based composite images”, manuscript as yet unpublished. 
Kuivaniemi-Smith, H.J., Nash, R.A., Brodie, E. R., Mahoney, G. and Rynn, C. (2014), "Producing facial composite sketches in remote Cognitive Interviews: A preliminary investigation”, Psychology, Crime and Law, Vol. 20, pp. 389-406.

Skelton, F.C., Frowd, C.D. and Speers, K.E. (2016), “The benefit of context for facial-composite construction”, Journal of Forensic Practice.

Steinberg, S. (2012), “Facial identification catalogs”, Available at samanthasteinberg.com/new_facial_identification_catalog.html.

Valentine, T. (1991), “A unified account of the effects of distinctiveness, inversion, and race in face recognition”, Quarterly Journal of Experimental Psychology - Human Experimental Psychology, Vol. 43A, pp. 161-204.

Valentine, T., Davis, J.P., Thorner, K., Solomon, C. and Gibson, S. (2010), "Evolving and combining facial composites: Between-witness and within-witness morphs compared", Journal of Experimental Psychology: Applied, Vol. 16, pp. 72-86.

Wells, G.L., Memon, A. and Penrod, S.D. (2007), "Eyewitness evidence: improving its probative value”, Psychological Sciences in the Public Interest, Vol. 7, pp. 45-75. 


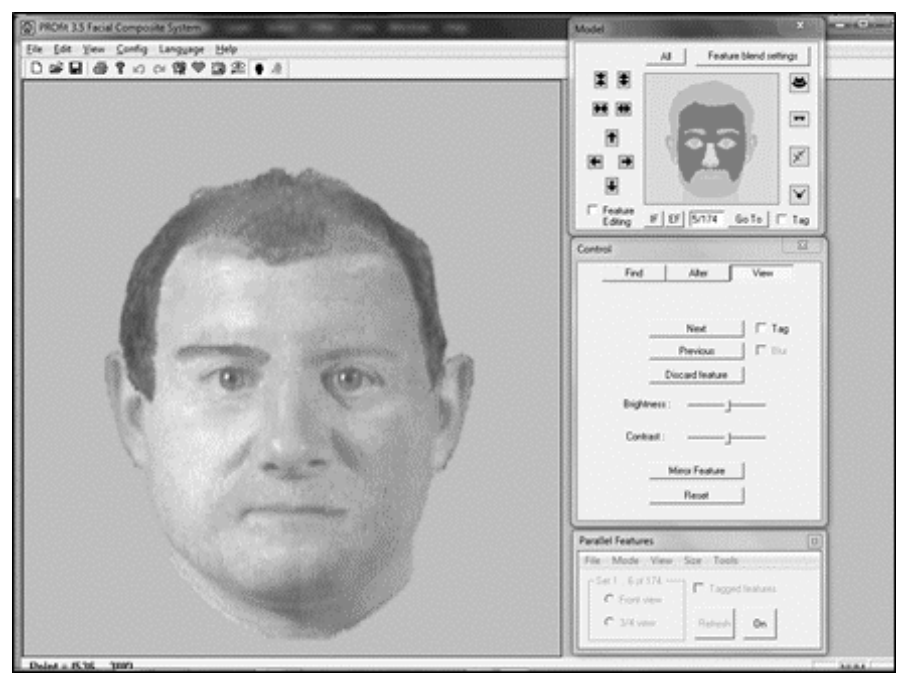

Figure 1. PRO-fit screenshot showing a full face within which witnesses select facial features. In this example, the 'face shape' (shown in dark grey [red when viewed in colour] in the Model dialog, top right) is being selected. 


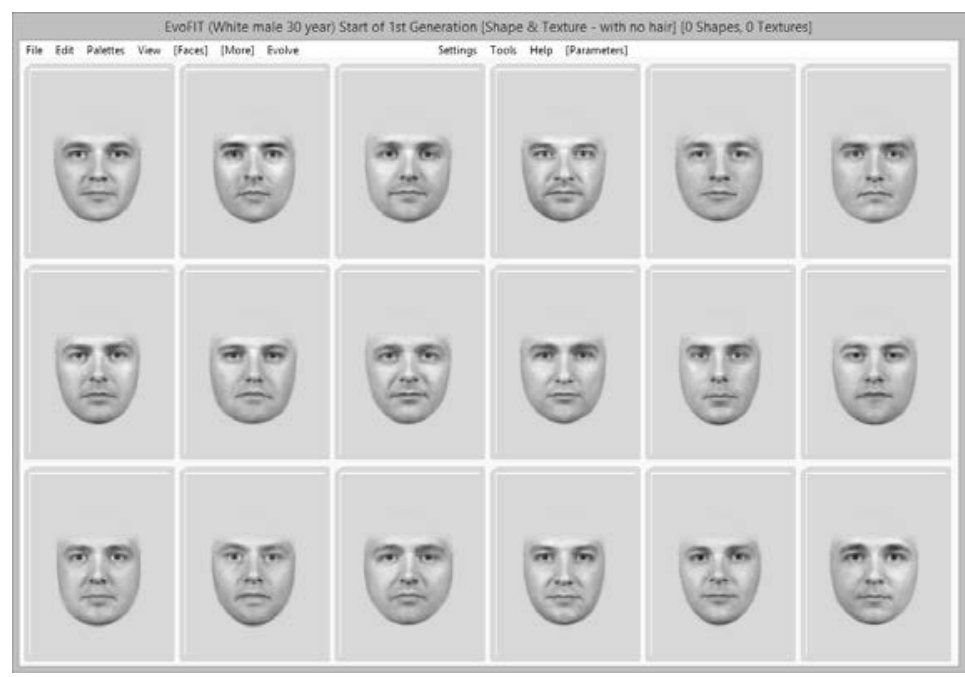

Figure 2. Initial EvoFIT screen (for the 30-year white-male database) showing an array of internal features that differ by facial shape and texture. 


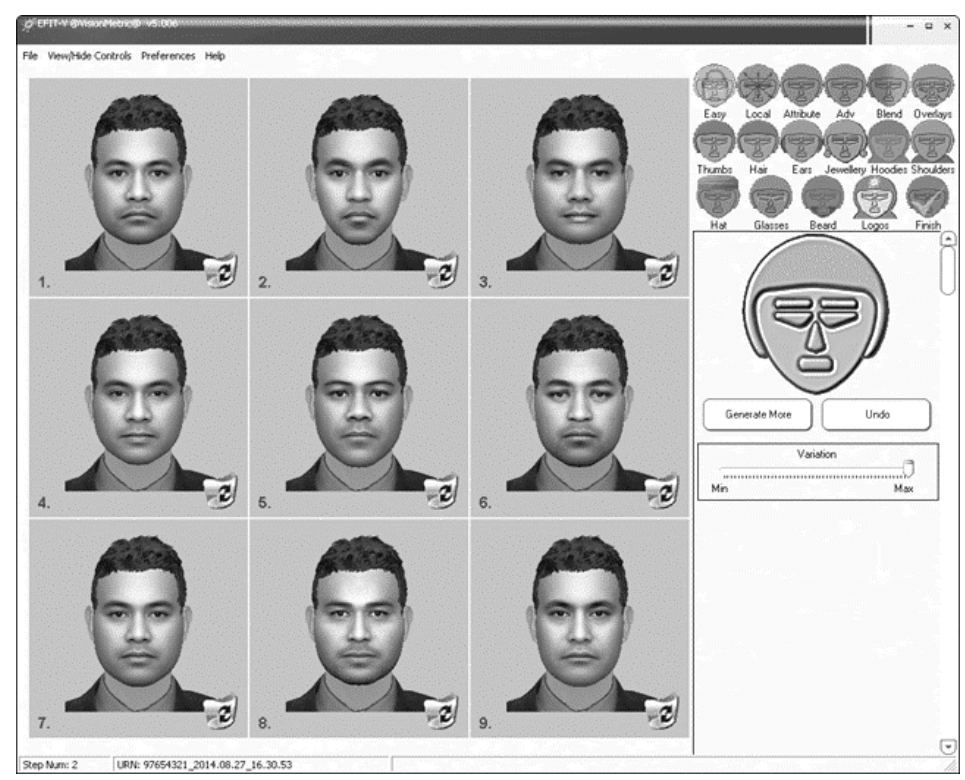

Figure 3. EFIT-V screen showing an array of faces that differ in shape and internal features. With courtesy of VisionMetric Ltd.

i Note that this novel face-construction procedure for a feature system does not appear to be effective unless the full HCI has been administered. Practitioners should continue to use the existing (whole-face) construction procedure following a face-recall CI. 